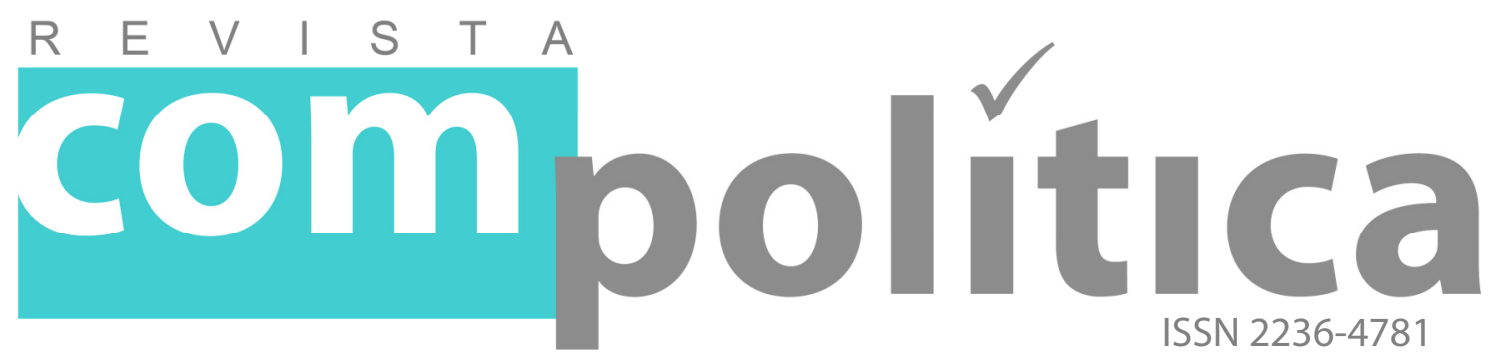

ALDÉ, Alessandra

Professora e pesquisadora do PPGCOM-Uerj, bolsista Prociência (Faperj/Uerj). Presidente da Compolítica e coordenadora do Diretório de Teses e Dissertações em Comunicação e Política. <a.alde@uol.com.br>

CHAGAS, Viktor

Professor do Departamento de Estudos Culturais e Mídia da UFF, coordenador da graduação em Estudos de Mídia. Responsável pelo planejamento de interface e banco de dados do Diretório de Teses e

Dissertações em Comunicação e Política. <viktor@midia.uff.br>

SANTOS, João Guilherme Bastos dos Mestrando em Comunicação (Uerj), bolsista Capes. Editor do Diretório de Teses e Dissertações em Comunicação e Política.

<gui_bsantos@hotmail.com>

\title{
Teses e dissertações defendidas no Brasil (1992-2012): um mapa da pesquisa em comunicação e política
}

RESUMO

Este relatório propõe uma primeira análise dos dados compilados para o Diretório Permanente de Teses e Dissertações da Compolítica, mantido pela Associação dos Pesquisadores Brasileiros em Comunicação e Política. O Diretório é um repositório digital de conteúdos de pesquisa relacionados ao tema, com escopo institucional e exaustivo, isto é, aberto a novas submissões. A partir de um corpus inicial de mais de 600 títulos já cadastrados na base de dados, este artigo pretende oferecer uma análise preliminar da pesquisa pós-graduada produzida no país na interface disciplinar da Comunicação e Política, com foco no período de 1992 a 2012, em que se concentram os dados disponíveis digitalmente e 0 maior volume de produção. A proposta do trabalho, portanto, é debater as linhas de atuação dos temas, instituições e pesquisadores da especialidade e perceber, por meio delas, como se configura o campo de pesquisa sobre o eixo da Comunicação e Política no Brasil, compreendendo de forma abrangente as redes de pesquisadores, seus laços e influências, bem como suas tendências históricas e institucionais.

Palavras-chaves: Comunicação política, teses e dissertações, Compolítica.

\section{ABSTRACT}

This report proposes an initial analysis of data collected for the Permanent Directory of Theses and Dissertations from Compolítica, the Brazilian Association of Political Communication Scholars. The Directory is a digital repository of research content related to the topic, with institutional and comprehensive scope, that is, open to new submissions. From an initial corpus of over 600 titles already registered in the database, this article aims to provide a preliminary examination of postgraduate research produced in the country in the disciplinary interface of Communication and Politics, focusing on the period 1992-2012, in which the data is concentrated and when there is higher output available. The purpose of this study, therefore, is to discuss the themes, institutions and researchers and map, through them, the conformation of the field of Communication and Politics in Brazil, comprising the networks of researchers, their ties and influences, as well as their historical and institutional trends.

Keywords: Political communication, theses and dissertations, Compolítica. 


\title{
Teses e dissertações defendidas no Brasil (1992-2012): um mapa da pesquisa em comunicação e política
}

\section{[Masters and doctorate theses in Brazil (1992-2012): a map of political communication research]}

\author{
ALDÉ, Alessandra \\ CHAGAS, Viktor \\ SANTOS, João Guilherme Bastos dos
}

1. Introdução: princípios e metodologia de inclusão no Diretório de Teses e Dissertações em Comunicação e Política

Associação Brasileira de Pesquisadores de Comunicação e
Política (Compolítica) publicou, em maio de 2013, seu Diretório de Teses e Dissertações, com o objetivo de mapear todos os trabalhos de fim de curso dos programas de pós-graduação reconhecidos no Brasil. Iniciado em 2011, o trabalho de localização e coleta de informações sobre cada tese e dissertação ainda está em curso e é permanente, na medida em que a equipe continua vasculhando áreas afins e novas instituições, ao mesmo tempo em que novos títulos vão sendo defendidos. O propósito do Diretório é ser uma referência para os estudos na área, e seu banco de dados traz informações sobre o título, autor, orientador, instituição, resumo e palavras-chave, bem como o ano de defesa e uma classificação segundo os nove temas da Compolítica, tais como definidos nas ementas dos respectivos GTs: Comunicação e Democracia; Mídia e Eleições; Comunicação Institucional e Imagem Pública; Internet e 
Política; Comunicação e Sociedade Civil; Cultura Política, Comportamento e Opinião Pública; Políticas de Comunicação; Jornalismo Político; Propaganda e Marketing Político .

No presente artigo, apresentamos alguns resultados da análise das teses e dissertações compiladas até o momento, no total de 635, sendo 140 teses e 495 dissertações ${ }^{2}$. Optamos por recortar o período de 1992 a 2012, últimos vinte anos, cobrindo importante período de crescimento e amadurecimento da especialidade. A análise dos resultados será principalmente quantitativa e descritiva, e o que apresentamos brevemente a seguir, à guisa de metodologia, é o percurso de busca e localização dos trabalhos, que justifica, para além do número já significativo de títulos, também a representatividade deste corpus.

Um primeiro esforço de busca consistiu no envio de e-mails para os pesquisadores da área, através das listas da Compolítica, Compós, Anpocs e $\mathrm{ABCP}$, pedindo que retornassem ao endereço fornecido os dados de seus próprios trabalhos de conclusão e os de seus orientandos. A resposta espontânea, no entanto, foi muito baixa, e passamos à investigação mais ativa dos bancos disponíveis, por meio das Bibliotecas Digitais de Teses e Dissertações (BDTD) das Universidades brasileiras. O primeiro levantamento concentrou-se nas Universidades com pós-graduações mais consolidadas, não apenas em Comunicação, mas também os de Antropologia, Sociologia, Ciência Política, História e outros, primeiramente no Rio de Janeiro e incluindo progressivamente os demais Estados e regiões. Uma importante limitação evidenciou-se já neste momento, que é a existência de bancos incompletos e desatualizados nos sites dos próprios Programas - em que pese a importância estratégica cada

${ }^{1} \mathrm{O}$ Diretório também fornece o link para a íntegra do trabalho, geralmente no banco de teses da própria instituição, da Capes ou, quando não disponível, em acervos alternativos.

${ }^{2} \mathrm{O}$ banco de dados, embora ainda desatualizado em relação a 2012, apresenta totais bem maiores que os títulos disponíveis no catálogo online do próprio Diretório. Problemas técnicos devidos ao volume de dados limitaram até o momento a incorporação de todos os títulos já pesquisados. 
vez maior deste tipo de visibilidade para a circulação da produção acadêmica e avaliação dos Programas.

Dada a dimensão do corpus proposto, no entanto, decidimos adotar outra estratégia em paralelo ao mapeamento dos Programas. A equipe elaborou uma lista de pesquisadores da especialidade, a partir do levantamento dos participantes do GT de Comunicação e Política da Compós disponíveis no site da Associação. Lista equivalente foi feita para os GTs e STs de diferentes nomes que exerceram papel equivalente na Anpocs. Essa busca concentrou-se nos anos de 2000 a 2012, para os quais os Congressos disponibilizaram programação online. A partir deste viés institucional, considerando como pesquisadores reconhecidos da área todos os que tiveram trabalhos aceitos nos principais congressos das duas principais Associações de pesquisa pós-graduada, passamos a investigar o currículo Lattes de cada um deles e incluir no Diretório, quando pertinentes: (a) os trabalhos de conclusão de Mestrado e Doutorado dos próprios pesquisadores; (b) os nomes dos respectivos orientadores, dando origem a nova busca idêntica; (c) os trabalhos de conclusão dos orientandos de cada pesquisador. Os Programas em que tais trabalhos foram defendidos também foram sendo incorporados à amostra, gerando nova busca institucional, com o objetivo de identificar outros orientadores na especialidade.

Nessa etapa, outra dificuldade se fez presente: muitas vezes o currículo Lattes dos orientadores não é preciso nas informações que publica sobre os trabalhos orientados. Encontramos vários casos em que o título do trabalho divulgado pelo orientador não coincide com o título final do trabalho defendido; conseguimos contornar esta dificuldade checando as informações, a partir do nome dos autores, no banco de Teses da Capes. Uma hipótese para explicar esta falta de consistência é o modo de preenchimento do currículo Lattes, que permite ao orientador atualizar o trabalho como "orientação concluída" sem que seja necessário mudar o título, muitas vezes um 
"título de trabalho" mais genérico, que foi abandonado pelo autor na versão final.

Ao analisar os resultados destas primeiras linhas de investigação, no entanto, percebemos que havia um vácuo significativo de trabalhos da década de 90, principalmente pela dificuldade de acesso a material ainda não disponível online, seja das IES como dos Congressos. Recorremos novamente ao Banco de Teses da Capes: a partir de uma busca geral com a combinação dos termos "política" e "comunicação", verificamos a cada ano, a partir de 1992, todos os títulos pertinentes. Os pesquisadores entraram em todos os itens que não fossem evidentemente alheios à especialidade, e verificaram, a partir do resumo e palavras-chave, a pertinência do trabalho. Com isso, ampliamos o escopo do Diretório para além das redes de atuação acadêmica contemporâneas mais evidentes.

Apesar de já contarmos, portanto, com uma amostra bastante representativa, cabe enfatizar que se trata de um conjunto dinâmico de dados, em constante atualização e revisão - e que estamos cientes do caráter parcial e provisório das análises oferecidas aqui.

\section{Evolução dos trabalhos de comunicação e política no contexto das Áreas}

De acordo com a Capes, entre 1996 e 2012 foram defendidas 2103 teses de doutorado e 6688 dissertações de mestrado em Comunicação, totalizando 8791 trabalhos. Na pós-graduação em Ciência Política, o volume total é menor: 2335 dissertações e 617 teses, num total de 2952 trabalhos $^{3}$. O mapeamento realizado para o

\footnotetext{
${ }^{3}$ A avaliação da Capes é realizada regularmente desde 1976, tendo passado por período de coleta anual, bienal e finalmente trienal (a partir de 1998). Os dados equivalentes ao período 1992-1998 (Ciência Política) e 1992-1996 (Comunicação) não foram fornecidos pela agência. Os dados apresentados aqui dizem respeito apenas a trabalhos diretamente vinculados às áreas de Comunicação e Ciência
} 
presente artigo contempla, principalmente, trabalhos oriundos destes dois universos, e nos interessa, em primeiro lugar, cotejar a evolução da produção científica relacionada à especialidade da Comunicação Política com suas principais Áreas institucionais, visualizada no Gráfico 1 (G1).

Gráfico G1: Teses e dissertações - evolução Comunicação, Ciência Política e Comunicação e Política
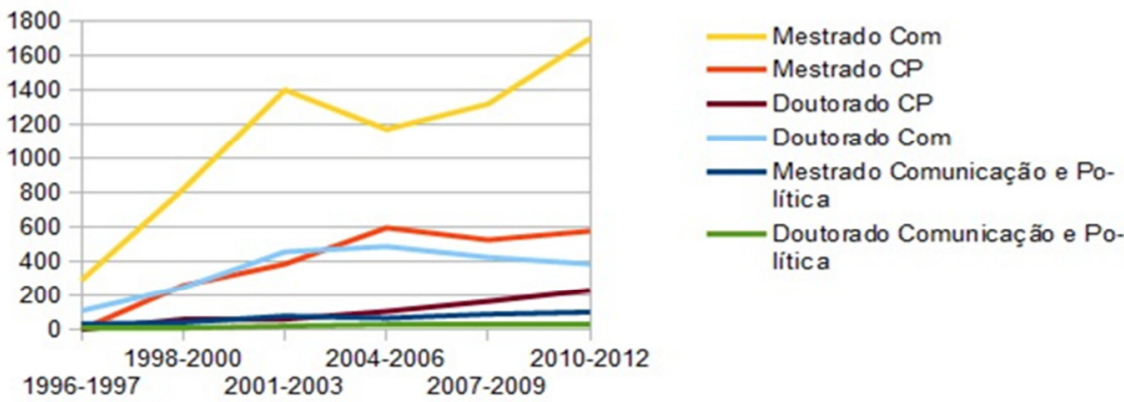

1996-1997 2001-2003 2007-2009

A grande expansão de titulações, em particular de Mestrado e na Área de Comunicação, coloca em perspectiva o avanço da nossa especialidade. Dentro do quadro de forte crescimento das pósgraduações, a Comunicação e Política ocupa um lugar modesto. Considerando, no entanto, a multiplicidade de especialidades que as disciplinas comportam (a título de ilustração, são 15 Grupos de Trabalho na Compós, 15 Áreas Temáticas na ABCP e bem 39 Seminários Temáticos no último Congresso da ANPOCS), trata-se de um nicho de interesse que se mantém ativo e relevante, quantitativamente, ao longo destas duas décadas.

O nosso mapeamento abrangeu, entre 1992 e 2012, 635 trabalhos, entre teses e dissertações. Se considerarmos apenas os trabalhos defendidos entre os anos de 1996 e 2009, correspondentes aos dados 
da Capes, encontramos a maioria absoluta da produção, no total de 576 trabalhos - uma proporção de 6,5\% em relação ao total da área de Comunicação, ou 19,4\% em relação à Ciência Política. O conjunto dos trabalhos compilados pela Compolítica, que está sendo considerado aqui, é naturalmente mais abrangente do que cada área específica, pois inclui trabalhos das duas disciplinas e de outras mais; há, proporcionalmente, mais trabalhos de Comunicação, o que explica o superdimensionamento, em relação aos trabalhos apenas de Ciência Política. Importa ressaltar, no entanto, que se trata de trabalhos com interface e interesse para a área, muitas vezes com bancas compostas por pesquisadores das duas disciplinas. Portanto, estamos apresentando estas comparações proporcionais para ilustrar a grandeza relativa desta produção.

No caso da Comunicação, de acordo com os dados dispostos no quadro abaixo (Q1), a produção sobre o tema é mais intensa no período correspondente à avaliação bienal 1996-1997, seguido por uma oscilação razoavelmente equilibrada nos anos seguintes. Podese perceber também que as proporções correspondentes à produção da Área e aos trabalhos específicos da Comunicação e Política se mantém relativamente estáveis, mesmo em triênios de retração do volume total de trabalhos da área ${ }^{4}$.

\footnotetext{
${ }^{4}$ Lembremos que os números de 2012 do diretório ainda estão desatualizados e serão maiores.
} 
Quadro Q1: Comparativo entre teses e dissertações defendidas na área CSA1/Capes e no campo da Comunicação Política

\begin{tabular}{|c|c|c|c|c|c|c|c|c|c|}
\hline $\begin{array}{l}0 \\
\frac{0}{0} \\
0 \\
0 \\
0\end{array}$ & 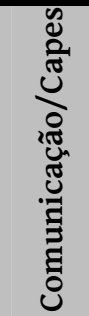 & 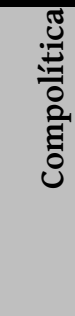 & do & 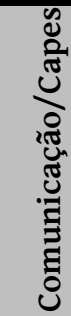 & 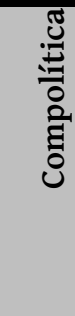 & do & 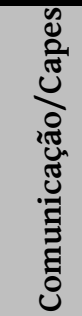 & 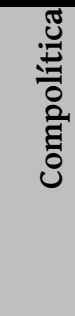 & do \\
\hline & 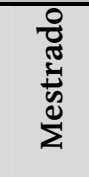 & 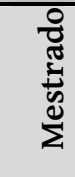 & & 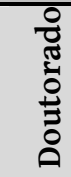 & $\begin{array}{l}0 \\
\frac{0}{0} \\
0 \\
0 \\
0 \\
0 \\
0\end{array}$ & & $\begin{array}{l}\vec{\pi} \\
\stackrel{\pi}{0} \\
\Leftrightarrow\end{array}$ & $\begin{array}{l}\bar{\pi} \\
\stackrel{5}{0} \\
\Leftrightarrow\end{array}$ & \\
\hline 1996-1997 & 290 & 32 & $11,0 \%$ & 109 & 9 & $8,3 \%$ & 399 & 41 & $10,3 \%$ \\
\hline $1998-2000$ & 817 & 43 & $5,3 \%$ & 246 & 14 & $5,7 \%$ & 1063 & 57 & $5,4 \%$ \\
\hline $2001-2003$ & 1398 & 93 & $6,7 \%$ & 455 & 22 & $4,8 \%$ & 1853 & 115 & $6,2 \%$ \\
\hline $2004-2006$ & 1169 & 75 & $6,4 \%$ & 486 & 28 & $5,8 \%$ & 1655 & 103 & $6,2 \%$ \\
\hline $2007-2009$ & 1317 & 98 & $7,4 \%$ & 423 & 30 & $7,1 \%$ & 1740 & 128 & $7,4 \%$ \\
\hline $2010-2012$ & 1697 & 101 & $6,0 \%$ & 384 & 31 & $8,1 \%$ & 2081 & 132 & $6,3 \%$ \\
\hline
\end{tabular}

Fonte: Coordenação CSA1/Capes/MEC e Compolítica

Em relação à Área de Ciência Política, a produção da especialidade se destaca em termos quantitativos. Cabe notar que muitos trabalhos de Ciência Política são defendidos em Programas mais genéricos de Ciências Sociais, e que os cursos de mestrado e doutorado na subárea tiveram um volume inicial menor e crescimento posterior, como se viu no Gráfico 1.

Nos anos para os quais dispomos de dados, a Comunicação Política se posiciona bem em relação ao conjunto das teses e dissertações em 
Ciência Política. No triênio 2001-2003, por exemplo, corresponde a 24,2\% das dissertações e 37,3\% das teses em Ciência Política. No cômputo total, a produção da especialidade se manteve numa proporção entre $15 \%$ e $26 \%$ em relação à subárea - dado ainda mais relevante quando observamos o crescimento constante da pósgraduação em Ciência Política, mesmo em relação à Comunicação, cujo ritmo exponencial de crescimento inicial arrefeceu nos triênios mais recentes, especialmente no que diz respeito ao doutorado (G1).

Quadro Q2: Comparativo entre teses e dissertações defendidas na área Ciência Política/Capes e no campo da Comunicação Política

\begin{tabular}{|c|c|c|c|c|c|c|c|c|c|}
\hline $\begin{array}{l}0 \\
0 \\
0 \\
0 \\
0 \\
0\end{array}$ & 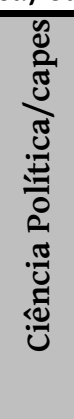 & 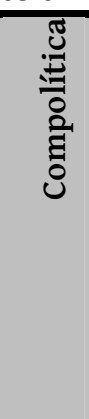 & वं & 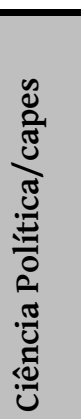 & 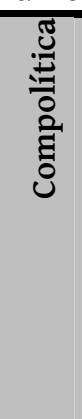 & $x^{\circ}$ & 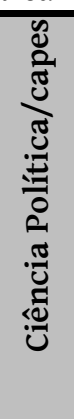 & 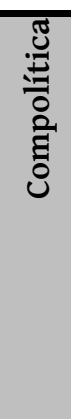 & $x^{\circ}$ \\
\hline & 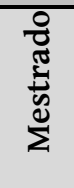 & 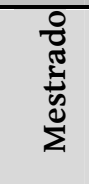 & & 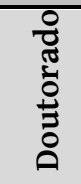 & 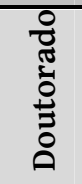 & & 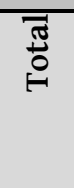 & $\begin{array}{l}\bar{\pi} \\
0 \\
0\end{array}$ & \\
\hline $1996-1997$ & - & 32 & - & - & 9 & - & - & 41 & - \\
\hline $1998-2000$ & 258 & 43 & $16,7 \%$ & 60 & 14 & $23,3 \%$ & 318 & 57 & $17,9 \%$ \\
\hline $2001-2003$ & 384 & 93 & $24,2 \%$ & 59 & 22 & $37,3 \%$ & 443 & 115 & $26,0 \%$ \\
\hline $2004-2006$ & 594 & 75 & $12,6 \%$ & 105 & 28 & $26,7 \%$ & 699 & 103 & $14,7 \%$ \\
\hline $2007-2009$ & 524 & 98 & $18,7 \%$ & 164 & 30 & $18,3 \%$ & 688 & 128 & $18,6 \%$ \\
\hline $2010-2012$ & 575 & 101 & $17,6 \%$ & 229 & 31 & $13,5 \%$ & 804 & 132 & $16,4 \%$ \\
\hline
\end{tabular}


Observando mais de perto o universo específico dos trabalhos mapeados pelo Diretório, que é o que nos interessa, o progresso é inegável. Em 1992, foi possível identificar apenas 12 trabalhos próximos ao universo de pesquisa em questão. Neste momento inicial, as poucas pós-graduações existentes, principalmente no nível de doutorado, forçam uma concentração de titulações nestes Programas pioneiros, em ambas as Áreas. São instituições que permanecerão ativas ao longo do tempo: sete das dez universidades com mais contribuições totais ao Diretório já possuíam trabalhos na área em 1992 e possuem os trabalhos mais antigos entre os recuperados em cada categoria temática. São elas UnB, UFRJ, USP, UFMG, UMESP, PUC-SP e UFRGS.

Quadro Q3: Teses e dissertações em Comunicação Política defendidas por ano

\begin{tabular}{|c|c|c|c|}
\hline Ano & Dissertações & Teses & Total \\
\hline 1992 & 4 & 0 & 4 \\
\hline 1993 & 2 & 0 & 2 \\
\hline 1994 & 12 & 3 & 15 \\
\hline 1995 & 19 & 2 & 21 \\
\hline 1996 & 11 & 5 & 16 \\
\hline 1997 & 21 & 3 & 24 \\
\hline 1998 & 13 & 2 & 15 \\
\hline 1999 & 18 & 9 & 27 \\
\hline 2000 & 10 & 2 & 12 \\
\hline 2001 & 20 & 6 & 26 \\
\hline 2002 & 32 & 6 & 38 \\
\hline 2003 & 26 & 8 & 34 \\
\hline 2004 & 32 & 7 & 39 \\
\hline
\end{tabular}




\begin{tabular}{llll}
\hline 2005 & 15 & 10 & 25 \\
\hline 2006 & 19 & 10 & 29 \\
\hline 2007 & 21 & 13 & 34 \\
\hline 2008 & 37 & 8 & 45 \\
\hline 2009 & 31 & 6 & 37 \\
\hline 2010 & 28 & 5 & 33 \\
\hline 2011 & 29 & 14 & 23 \\
\hline 2012 & 15 & 5 & \\
\hline Fonte: Compolítica & & & \\
\hline
\end{tabular}

Fonte: Compolítica

Algumas delas já contavam com Programas de Pós-Graduação relacionados com Ciência Política (UnB e UFRGS) ou Comunicação/Semiótica (UFRJ e PUC-SP). No entanto, alguns dos primeiros trabalhos identificados em Universidades que mais tarde viriam a contribuir ativamente através de Programas de PósGraduação em Comunicação ou Ciência Política vieram de outras áreas de pesquisa em que já havia cursos afins, como o Programa de Pós-Graduação em Relações Internacionais (UnB), Política Social (UnB), Sociologia e Antropologia (UFRJ), Sociologia (UFMG), Educação (UMESP), História (PUC-SP e UFG). Entre as outras áreas que contribuem com trabalhos em universidades com menor número total de contribuições destacam-se como pioneiros o PPG em História da Universidade Federal de Goiás (1992), o PPG em Administração Rural e Comunicação Rural da Universidade Federal de Pernambuco (1992), o PPGraduação em Psicologia Social e Desenvolvimento Humano da Universidade Federal da Paraíba (1994) e o PPG em Sociologia Política da UFSC (1995).

O pico da produção, no período analisado, se deu em 2011, com 52 trabalhos defendidos, mesmo ano em que ocorre o pico de defesas de tese, com 16 trabalhos desta natureza, conforme o quadro a seguir (Q3). Além da expansão dos PPGs e da consolidação da especialidade 
nas Associações ${ }^{5}$, supomos que haja algum impacto da atividade político-eleitoral do país na produção acadêmica da especialidade, o que pode contribuir para explicar a concentração de trabalhos em torno de anos em que há acontecimentos políticos de grande repercussão, como eleições e grandes escândalos.

Não é possível fazer uma associação linear, até pelos prazos distintos dos cursos, mas chamam a atenção, por exemplo, os picos de defesas nos anos imediatamente posteriores às eleições durante a década de 90, bem como uma grande onda de produção entre os anos de 2001 e 2004; e um novo pico de crescimento em 2011. É possível analisar melhor estas tendências explorando algumas das questões relativas à agenda temática observada nos trabalhos, tarefa a que nos dedicamos na sequência.

\section{A agenda temática da Comunicação e Política ao longo do tempo}

A classificação das teses e dissertações de acordo com as nove categorias temáticas, de responsabilidade do editor do Diretório, foi feita com base no cruzamento entre as ementas publicadas no site da Associação, definidas por cada coordenador, e o resumo/palavraschave das teses e dissertações analisadas. Nos poucos casos em que isso era insuficiente e havia uma versão completa online, a Introdução do trabalho foi utilizada como critério decisivo. Considerando a redundância de temas similares em diferentes ementas, e a possibilidade de um trabalho com o fôlego de uma tese ou dissertação se encaixar em mais de um deles, foi aberta a

\footnotetext{
${ }^{5} \mathrm{Na}$ Compós, o GT de Comunicação e Política existe desde a fundação da entidade, em 1991. Na ANPOCS, GTs dedicados ao assunto funcionaram ininterruptamente, embora com denominações ligeiramente diferentes, desde 1998. A Compolítica foi fundada em 2006, e a ABCP contempla a Área Temática "Comunicação política e opinião pública" desde 2008.
} 
possibilidade de classificar um mesmo trabalho como pertinente a até quatro categorias ${ }^{6}$.

O número total de trabalhos em cada categoria a partir de 1992 é de 220 em Comunicação e Democracia, 188 em Comunicação e Sociedade Civil, 179 em Jornalismo Político, 144 em Cultura Política, Comportamento e Opinião Pública, 131 em Comunicação Institucional e Imagem Pública, 119 em Mídia e Eleições, 94 em Políticas da Comunicação, e 87 em Propaganda e Marketing Político e 67 em Internet e Política. Mas as nove categorias temáticas estão presentes de maneira diferente ao longo do tempo, contribuindo para elucidar a agenda de pesquisa da especialidade. É possível observar, em primeiro lugar, a ampliação do leque temático da área, de apenas seis temas, em 1992, para a participação efetiva de todos os nove nos últimos cinco anos analisados.

\footnotetext{
${ }^{6} \mathrm{O}$ conceito de accountability, por exemplo, é apontado como ramo de interesse de quatro dos nove GTs: processos de accountability no GT1; accountability eleitoral no GT2; accountability eletrônico no GT4; e jornalismo e accountability no GT8. Cabe ressaltar que apenas uma minoria dos trabalhos precisou ser classificada em mais de duas categorias. A distribuição foi de $14 \%$ dos trabalhos em 1 categoria; $40 \%$ em 2 categorias; $33 \%$ em 3 categorias; e 13\% em 4 categorias.
} 


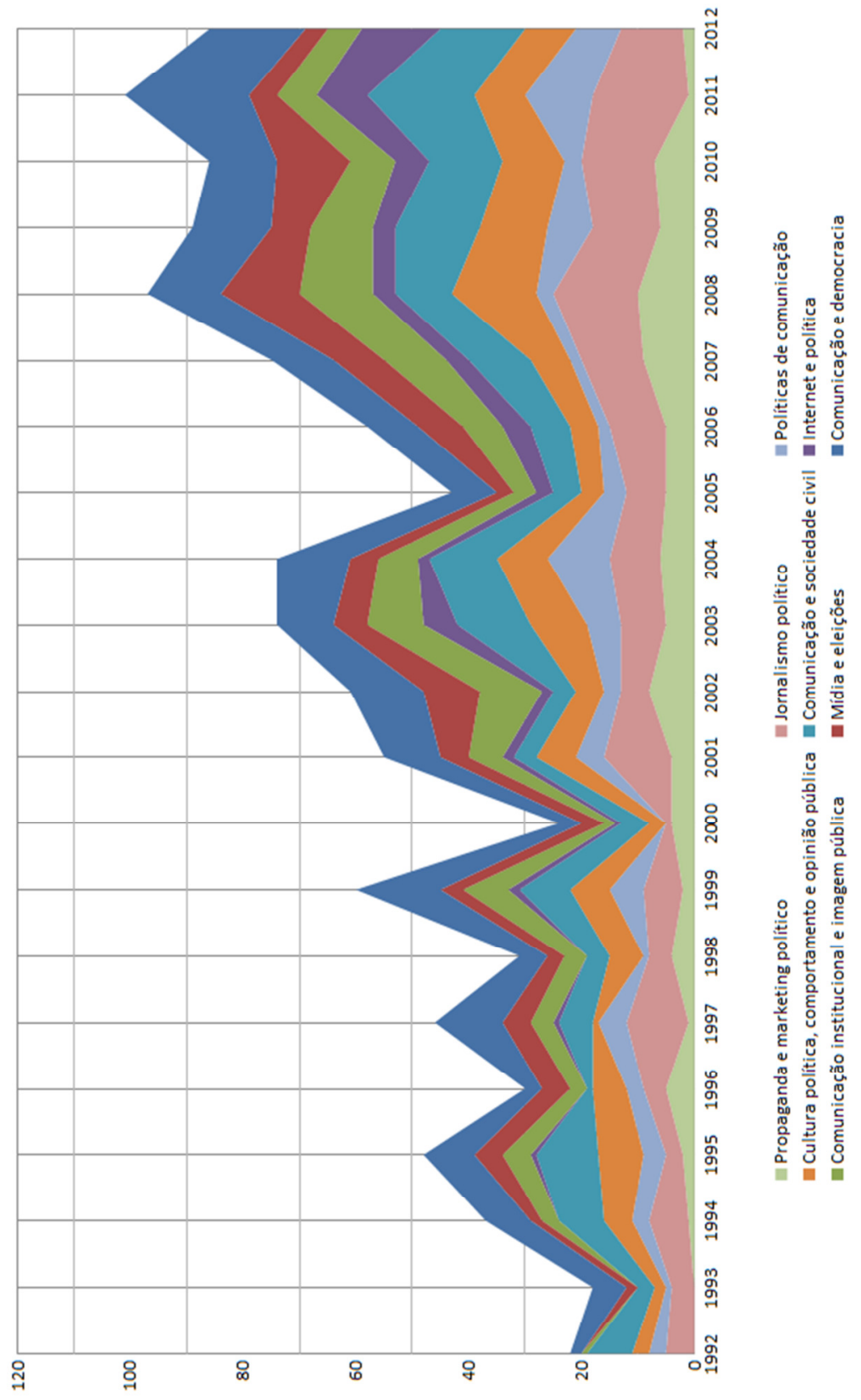

Fonte: Compolítica.

É interessante notar a forte presença dos temas teóricos de fundo, “Comunicação e democracia" e "Comunicação e sociedade civil", ao longo de todo o período, tornando-se especialmente relevantes, em 
relação ao conjunto, de 2008 em diante. O próprio nível acadêmico dos trabalhos sugere a presença de algum lastro teórico, representado pela classificação nestas categorias mais abstratas. Outro caso de presença constante na especialidade, pouco sujeita às oscilações negativas do conjunto, é a categoria “Jornalismo político", que se destaca em anos como 1994, 1997, 2001 e 2005, assumindo grande proeminência daí em diante. "Cultura política”, por sua vez, destoa da oscilação do conjunto apenas em 1996 e 1998, anos em que sua participação relativa cresce mais que as outras categorias. Em geral, no entanto, acompanha o ritmo de evolução da especialidade.

Outras categorias temáticas têm uma evolução menos constante. "Comunicação institucional e imagem pública" e "Mídia e eleições" são temas que, ausentes ou tímidos nos primeiros anos, se consolidaram ao longo do tempo, com picos coincidentes em 2002 e 2008; em dinâmica distinta à da categoria "Propaganda e Marketing político", que em muitos anos segue tendência oposta à da maioria dos temas, crescendo, por exemplo, em 1996, 1998 e 2000, quando os outros temas diminuem; e tornando-se quase residual nos últimos dois anos, de grande crescimento geral da área. "Políticas da Comunicação", por sua vez, participa com menos intensidade do conjunto, respondendo por uma proporção pequena do total de trabalhos, mas tem dois momentos de crescimento relativo, em 2004 e 2008. Também é interessante acompanhar o surgimento e crescimento do tema "Internet e política", desde parcos trabalhos no fim dos anos 90 até se tornar um dos temas mais relevantes em 2012.

No tocante à relação entre instituições e categorias temáticas, a produção das universidades por categoria confirma a concentração de trabalhos em poucas universidades e indica, em geral, a concentração destes trabalhos em poucas categorias temáticas específicas. A maioria (21 de 32) das universidades não ultrapassa a marca de 10 produções enquadradas em uma mesma categoria. Entre as 11 que ultrapassam esta marca, apenas quatro o fazem em mais da 
metade das categorias, com a UnB e a UFBA superando a marca de 10 produções enquadradas em sete categorias diferentes. Nas seis universidades que lideram o ranking de contribuições totais (soma das pontuações em todas as categorias), a relação entre a categoria com mais produções e a com menos pode ser visualizada no Quadro 4, abaixo.

Quadro Q4: Categorias temáticas por instituição

\begin{tabular}{|c|c|c|c|}
\hline IES & Maior categoria & Menor categoria & Dif \\
\hline \multirow[t]{2}{*}{ UnB } & 26 & 2 & 24 \\
\hline & Comunicação e democracia & Internet e política & \\
\hline \multirow[t]{2}{*}{ UFBA } & 28 & 4 & 24 \\
\hline & Comunicação e democracia & $\begin{array}{l}\text { Com. inst. e imagem } \\
\text { pública }\end{array}$ & \\
\hline \multirow[t]{2}{*}{ UMESP } & 29 & 0 & 29 \\
\hline & $\begin{array}{l}\text { Propaganda e marketing } \\
\text { político }\end{array}$ & Internet e política & \\
\hline \multirow[t]{2}{*}{ UFRJ } & 21 & 5 & 16 \\
\hline & Comunicação e sociedade civil & $\begin{array}{l}\text { Propaganda e marketing } \\
\text { político }\end{array}$ & \\
\hline \multirow[t]{2}{*}{ USP } & 17 & 4 & 13 \\
\hline & Jornalismo político & Mídia e eleições & \\
\hline \multirow[t]{2}{*}{ UFMG } & 26 & 1 & 25 \\
\hline & Comunicação e sociedade civil & Políticas de comunicação & \\
\hline
\end{tabular}

Fonte: Compolítica.

Estas seis universidades dividem entre si a liderança em cada uma das nove categorias, com exceção da UFRJ $\left(4^{\circ}\right)$ e USP $\left(5^{\circ}\right)$, que não assumem lideranças. Estas exceções se devem ao fato da produção de ambas ser mais dispersa pelas categorias, se comparada às demais 
universidades. Isso fica evidente no fato de a UFRJ ter o quarto maior número de contribuições totais (100), com mais de 10 trabalhos em pelo menos cinco categorias, enquanto outras universidades com menos contribuições em um número igual ou menor de categorias assumem lideranças temáticas. Não por acaso, estas duas instituições são as únicas entre as seis com maior contribuição que possuem uma diferença inferior a 20 trabalhos entre a categoria com mais e a categoria com menos trabalhos registrados.

Para além da distribuição de temas cronológica e institucionalmente, a evolução das teses e dissertações está ligada de forma inevitável ao conjunto de professores orientadores responsáveis pelos trabalhos em Programas credenciados. A análise dos dados relativos às relações de orientação contribui para mapear a dinâmica dos estudos na área. 


\section{Genealogia das pesquisas em Comunicação Política no Brasil}

Os 635 trabalhos mapeados ao longo desta pesquisa correspondem a 573 autores diferentes, alguns deles com produções tanto de dissertações quanto de teses. Tais trabalhos foram orientados por 215 docentes, legando-nos um campo em que estão envolvidos 771 cientistas, 17 dos quais atuaram nos últimos anos tanto como autores quanto como orientadores, constituindo portanto uma camada geracional intermediária sobre a qual tratamos na sequência.

Dos 215 pesquisadores com orientações cujo foco são os estudos de Comunicação Política, nem todos figuram no universo de pesquisadores com maior produção sobre o tema. Esta afirmação se baseia na constatação de que a grande maioria tem somente uma orientação (122 pesquisadores). Parte da explicação pode ser atribuída à expansão recente do campo, com a constituição de novos doutores em condições de serem absorvidos institucionalmente e passar a orientar. Por outro lado, constatamos uma grande atuação de pesquisadores oriundos de outras especialidades para a condução de orientações pontuais ou esporádicas sobre o tema da Comunicação Política.

Com relação às instituições que abrigam estas pesquisas, no total, ao longo destes últimos 20 anos, tivemos 37 instituições com trabalhos mapeados. O crescimento novamente é evidente. Em 1992, apenas oito instituições tiveram trabalhos identificados no mapeamento: quatro na USP, dois na UFRJ e um nas demais (PUC-SP, UMESP, UFMG, UFG, UFPE e UFRGS). Em 2009, pela primeira vez, esta quantidade alcançou a marca de duas dezenas, resultado superado em 2011, com 21 instituições com trabalhos defendidos. Em 2011, também, temos o índice mais elevado de pesquisadores com orientações concluídas, 38. À primeira vista, poder-se-ia imaginar que o crescimento no quadro de docentes com orientações concluídas seguisse a quantidade de instituições com defesas na 
especialidade. No entanto, colocando-se lado a lado estes indicadores (Q5), o que se observa é que, embora ambos oscilem positivamente na maior parte dos casos, também varia a distribuição de pesquisadores em condições de orientar por instituição. O que temos, assim, é uma situação que se estende de um cenário mais concentrado, com somente um orientador para cada instituição, em 1993, para uma distribuição bastante mais equilibrada, com dois orientadores por instituição, em 1997, oscilando ainda ao longo dos demais anos em uma razão entre 1,33 e 1,88.

Quadro Q5: Quantidade de instituições com trabalhos defendidos e pesquisadores com orientações

\begin{tabular}{|c|c|c|}
\hline Ano & Instituições & $\begin{array}{r}\text { Pesquisadores com } \\
\text { orientações }\end{array}$ \\
\hline 1992 & 8 & 11 \\
\hline 1993 & 6 & 7 \\
\hline 1994 & 10 & 14 \\
\hline 1995 & 12 & 20 \\
\hline 1996 & 8 & 15 \\
\hline 1997 & 11 & 22 \\
\hline 1998 & 9 & 16 \\
\hline 1999 & 13 & 21 \\
\hline 2000 & 7 & 10 \\
\hline 2001 & 17 & 24 \\
\hline 2002 & 16 & 30 \\
\hline 2003 & 15 & 26 \\
\hline 2004 & 15 & 26 \\
\hline 2005 & 13 & 20 \\
\hline 2006 & 16 & 23 \\
\hline
\end{tabular}




\begin{tabular}{lcc}
\hline 2007 & 14 & 20 \\
\hline 2008 & 18 & 29 \\
\hline 2009 & 21 & 28 \\
\hline 2010 & 18 & 27 \\
\hline 2011 & 22 & 37 \\
\hline 2012 & 19 & 32 \\
\hline
\end{tabular}

Fonte: Compolítica

O tema da distribuição de pesquisadores por instituição também nos ajuda a compreender melhor, de certa forma, aquilo que identificamos como genealogias de autores. Conforme vemos a seguir, nem sempre as instituições com maior quantidade de trabalhos defendidos abrigam os pesquisadores com maior quantidade de orientandos. Para explorar estes entrecruzamentos de informações em minúcias, trataremos nas páginas a seguir das observações referentes à natureza dos trabalhos (se teses ou dissertações), aos orientadores e, finalmente, às instituições que os abrigam. 


\subsection{A natureza dos trabalhos}

As diferenças e peculiaridades no processo de pesquisa que resulta tanto em teses de doutorado quanto em dissertações de mestrado também incidem sobre os resultados. Por essa razão, conquanto o quadro Q5 nos apresente uma interessante relação entre instituições e pesquisadores com orientações, somente o detalhamento da natureza dessas orientações pode esclarecer determinados pontos. 0 quadro Q6 nos demonstra, por exemplo, que não há uma relação direta entre o crescimento das pesquisas em nível de mestrado e o subsequente acompanhamento deste crescimento em nível de doutorado no mesmo ano. Ao contrário, os anos em que houve maior número de defesas de dissertações (respectivamente 2008, 2002, 2004 e 2009) não foram os anos com maior quantidade de defesas de doutorado. Dois anos depois de cada um destes picos, no entanto, segue-se em geral um aumento também nas teses, sugerindo talvez a entrada conjunta de grupos de discentes interessados no tema nos dois níveis de seleção.

Quadro Q6: Quantidade de instituições com trabalhos defendidos por natureza de trabalho

\begin{tabular}{l|rr}
\hline Ano & $\begin{array}{r}\text { Instituições com defesas de } \\
\text { dissertação }\end{array}$ & $\begin{array}{r}\text { Instituições com defesas de } \\
\text { doutorado }\end{array}$ \\
\hline 1992 & 7 & 1 \\
\hline 1993 & 6 & 2 \\
\hline 1994 & 8 & 1 \\
\hline 1995 & 12 & 3 \\
\hline 1996 & 8 & 4 \\
\hline 1997 & 11 & 2 \\
\hline 1998 & 8 & 5 \\
\hline 1999 & 11 & \\
\hline
\end{tabular}




\begin{tabular}{|c|c|c|}
\hline 2000 & 6 & 2 \\
\hline 2001 & 14 & 4 \\
\hline 2002 & 14 & 7 \\
\hline 2003 & 15 & 5 \\
\hline 2004 & 14 & 4 \\
\hline 2005 & 11 & 6 \\
\hline 2006 & 12 & 9 \\
\hline 2007 & 10 & 7 \\
\hline 2008 & 18 & 6 \\
\hline 2009 & 18 & 7 \\
\hline 2010 & 18 & 4 \\
\hline 2011 & 18 & 7 \\
\hline 2012 & 16 & 6 \\
\hline
\end{tabular}

Fonte: Compolítica

De certa forma, como era de se esperar, as dissertações de mestrado concluídas impactam sobremaneira os números sobre a produção científica no campo. Por outro lado, podemos notar uma certa estabilidade com relação a orientações desta natureza nos últimos anos, embora os dados de 2012 ainda estejam sujeitos a atualização com titulações ainda não incluídas no Diretório. No quadro Q7, podemos visualizar as instituições com mais defesas concluídas na especialidade, de acordo com a natureza dos trabalhos. Em geral, as instituições acumulam uma relação de $2 / 5$ no que se refere às defesas de mestrado para as defesas de doutorado. Ou seja, para cada duas teses defendidas na área, são cinco as dissertações. Isto ocorre para instituições como UFRJ $(0,38)$, UFBA $(0,42)$ e PUC-SP $(0,43)$, por exemplo. A relação é mais igualitária em instituições como USP $(0,71)$ e Unicamp $(0,88)$, e menos igualitária em instituições como UnB $(0,11)$, Umesp $(0,12)$ e UFRGS $(0,21)$, o que provavelmente se explica 
pela historicidade dos programas de mestrado e doutorado ${ }^{7}$. Somente o antigo Iuperj (atual Iesp-Uerj) possui uma quantidade maior de teses do que dissertações.

Quadro Q7: Instituições com mais trabalhos defendidos por natureza do trabalho

\begin{tabular}{llllll}
\hline $\begin{array}{l}\text { Instituições com } \\
\text { mais defesas }\end{array}$ & \multicolumn{2}{c}{$\begin{array}{c}\text { Instituições com mais } \\
\text { defesas de dissertação }\end{array}$} & $\begin{array}{c}\text { Instituições com mais } \\
\text { defesas de tese }\end{array}$ \\
\hline UFRJ & 66 & UnB & 51 & USP & 20 \\
\hline UnB & 58 & UFRJ & 48 & UFRJ & 18 \\
\hline UFBA & 55 & Umesp & 41 & UFBA & 16 \\
\hline USP & 48 & UFBA & 38 & PUC-SP & 14 \\
\hline PUC-SP & 46 & PUC-RS & 33 & PUC-RS & 13 \\
\hline PUC-RS & 46 & PUC-SP & 32 & Iuperj & 11 \\
\hline Umesp & 45 & UFMG & 29 & Unicamp & 8 \\
\hline UFMG & 33 & USP & 28 & UnB & 6 \\
\hline UFF & 25 & UFF & 21 & UFF & 4 \\
\hline UFRGS & 23 & UFRGS & 19 & UFRGS & \\
\hline Fonte: & & & & & \\
\hline
\end{tabular}

Fonte: Compolítica

Proporções semelhantes são encontradas no quadro comparativo entre pesquisadores com orientações concluídas em nível de mestrado e doutorado separadamente (Q8), muito embora notemos com clareza que a ordem dos pesquisadores com mais orientações é distinta da ordem de instituições com mais defesas. Entre os dez primeiros pesquisadores com mais orientações de acordo com a natureza do trabalho, somente a metade figura tanto entre os

\footnotetext{
${ }^{7}$ Nos casos citados, o Ipol (UnB) teve aprovado seu doutorado somente em 2008, ao passo que o PPGCOM-UFRGS iniciou suas turmas de doutoramento em 2001. A Umesp possui doutorado desde 1995 e figura, aqui, como uma das poucas exceções à regra.
} 
orientadores com maior quantidade de dissertações orientadas quanto entre os orientadores com maior quantidade de teses orientadas.

Quadro Q8: Pesquisadores com mais orientações concluídas por natureza de trabalho

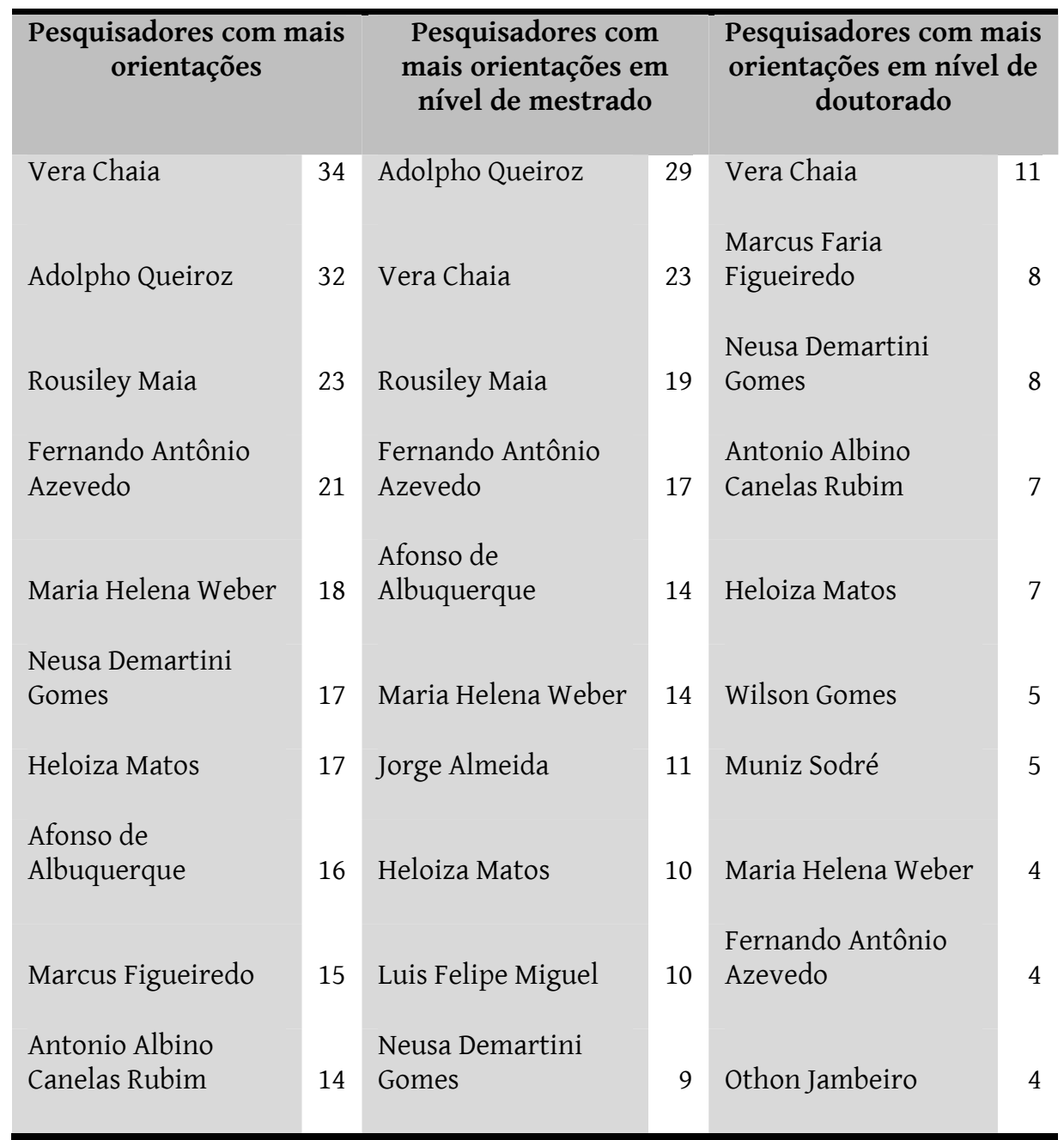

Fonte: Compolítica

Novamente, a quantidade dissertações é determinante para a "popularidade" do orientador, haja visto que oito entre os dez pesquisadores com mais orientações concluídas figuram na lista daqueles que mais orientaram em nível de mestrado - Rousiley Maia e Adolpho Queiroz, por exemplo, embora nem figurem entre os 10 com mais orientações de doutorado, se mantém bem colocados no 
cômputo geral graças ao volume de trabalhos de Mestrado. No doutorado, os orientadores têm menor concentração de teses, confirmando, talvez, a tendência mais generalista que percebemos nos cursos mais antigos, principalmente em seus primórdios. Neste sentido, podemos inferir que a produção da área se beneficia da demanda discente, que antecipa e justifica o estabelecimento de docentes mais especializados e grupos de pesquisa ativos. O passo seguinte é, pois, avaliarmos a relação entre estes pesquisadores que orientam trabalhos na área e seus orientandos ao longo do tempo. 


\subsection{O campo ao longo do tempo}

Se a natureza dos trabalhos de pós-graduação é capaz de nos apresentar aspectos importantes sobre as tendências do campo científico na área de Comunicação Política no país, devemos também reconhecer que tais tendências se subscrevem ao desenrolar histórico com igual peculiaridade. Nossa proposta agora é lançar um olhar apurado sobre que instituições são estas e que pesquisadores conduzem tais trabalhos. Tal esforço será capaz de delinear uma espécie de linha do tempo da pesquisa sobre Comunicação Política no Brasil, evidenciando tendências históricas ou conjunturais.

Em primeiro lugar, é incomum que uma mesma instituição sedie uma quantidade superior a cinco trabalhos no mesmo ano. Na realidade, foi possível mapear apenas dezesseis ocorrências do gênero ao longo destes vinte anos. As instituições com maior incidência de produção no mesmo ano são UFRJ e UnB (que aparecem na lista 16 vezes com mais de um trabalho defendido por ano), PUC-SP e UFBA (14 vezes cada), USP (12), UFMG (10), PUC-RS (9), UFF e Umesp (8 cada), Ufscar e UFRGS (7 cada). Mas as curvas de produção em cada instituição se alinham de acordo com múltiplas variáveis.

Critérios institucionais de clivagem, por exemplo, podem ocasionar mudanças na paisagem da pesquisa, como parece ser o caso da reforma de linhas de pesquisa por que passa o Programa de PósGraduação em Ciências da Comunicação da USP em 2006, e que, desde então, enfrenta baixos índices de produção na área temática pesquisada (G3). Na UFMG, o Programa de Pós-Graduação em Comunicação foi criado em 1995 e atingiu nota 5 na avaliação da Capes na avaliação do triênio 1998-2000. O curso de doutorado nesta mesma instituição foi aprovado somente em 2003, e, desde então, o que se vê é uma oscilação positiva na produção na área (cf. G3).

É possível também perceber de acordo com a radiografia abaixo (G3 e G4), a influência que pesquisadores em condições de orientar 
trabalhos na área e até que projetos específicos conduzidos por estes pesquisadores exercem sobre a conformação do campo. Assim, notamos que talvez um dos principais marcos para a produção de teses e dissertações vinculados à especialidade da Comunicação Política na UFBA tenha sido o projeto "Democracia Digital no Brasil", conduzido pelo professor doutor Wilson Gomes entre 2007 e 2010 (G4). Este mesmo período é responsável por uma curva ascendente na produção dentro da instituição (G3). Afastamentos para qualificação dos docentes ou condições profissionais específicas na trajetória destes pesquisadores também podem influenciar quantitativamente as orientações conduzidas por eles. Tal explicação pode dar conta da queda de produção na Pontifícia Universidade Católica de São Paulo no período entre os anos 1999 e 2000, e o aumento vertiginoso seguido de delicada queda de produtividade nos anos entre 2006 e 2008 (G3). Estes períodos correspondem, respectivamente, à livre-docência e ao pós-doutorado da professora doutora Vera Chaia (G4), uma das orientadoras, como vimos, mais prolíficas na área. Especialmente neste caso, o que vemos é uma oscilação absolutamente coincidente entre a instituição e a pesquisadora, de forma que a comparação nos permite afirmar que a docente é, em grande medida, responsável individualmente pelo deslanchar da área temática na pós-graduação da PUC-SP. 
Gráfico G3: Teses e dissertações defendidas ao longo do tempo por instituição

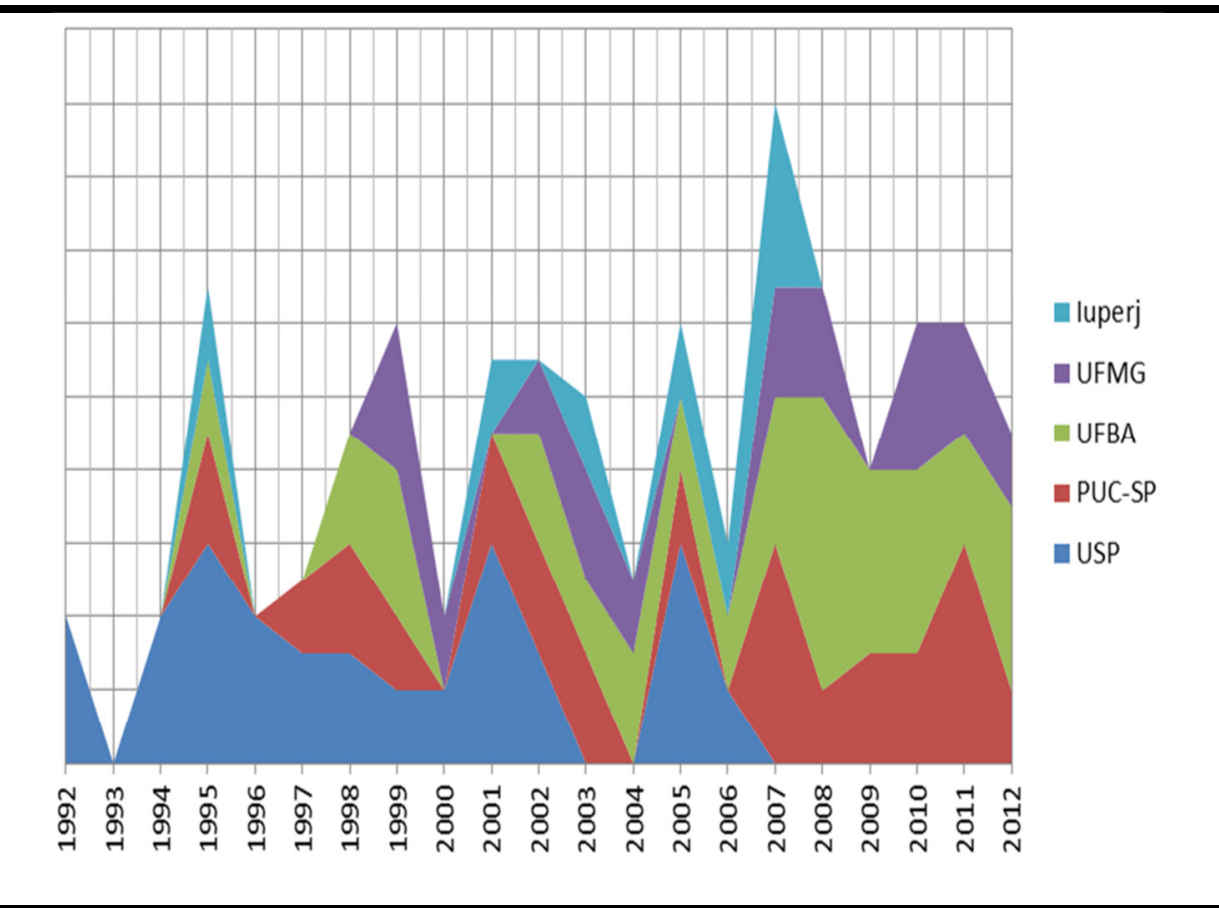

Fonte: Compolítica.

Gráficos G4: Pesquisadores com orientações concluídas ao longo do tempo

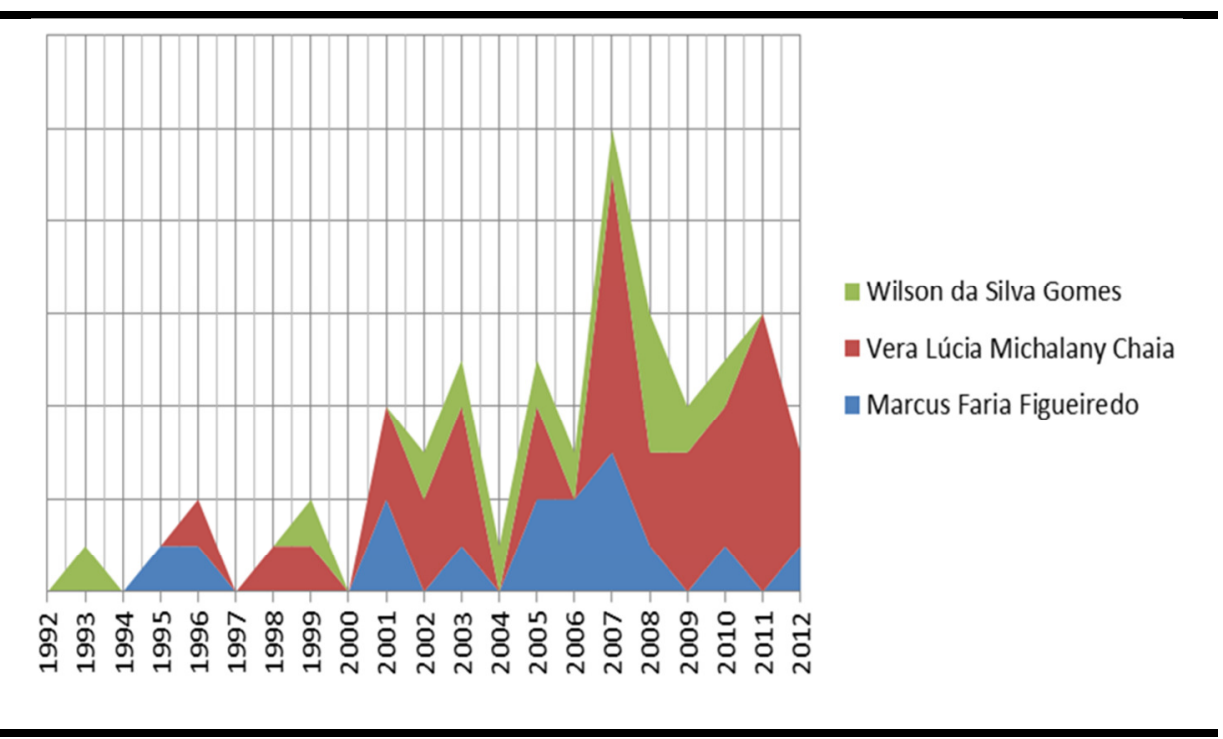

Fonte: Compolítica.

Um caso semelhante ao da professora Vera Chaia pode ser percebido na atuação do professor doutor Marcus Faria Figueiredo (G4), que, desde 1996, tem produção relevante na área temática de pesquisa em 
Mídia e Eleições, através do Doxa (Laboratório de Pesquisa em Comunicação Política e Opinião Pública), associado outrora ao Iuperj (G3) e atualmente ao Iesp-Uerj ${ }^{8}$. Os picos e declínios coincidentes em sua maioria apontam para uma participação relevante do pesquisador na formação de diversos quadros. Em particular, este caso nos interessa pela emblemática configuração dos pesquisadores formados pela instituição, alguns dos quais hoje operam como uma espécie de camada geracional intermediária, orientando quadros ainda mais novos nos programas a que se credenciaram. Dessa forma, é possível perceber através da relação entre orientadores e autores de teses e dissertações defendidas na área uma certa conformação genealógica cuja análise pode ser particularmente proveitosa para compreendermos também como se desenham os interesses de pesquisa no campo.

\subsection{Genealogias e redes de pesquisa}

Um olhar atento sobre a relação entre orientadores e orientandos na área nos permite atravessar a falsa impressão de que estamos diante de uma média de um orientador para cada três autores. Na realidade, o que temos é um quadro bastante mais aglutinador, dando conta de pesquisadores que se tornam referência ao longo do tempo e, por consequência, apresentam uma alta concentração de orientações ao seu redor, enquanto uma grande maioria apenas orientou um

\footnotetext{
${ }^{8} \mathrm{O}$ atual Iesp-Uerj concentra pesquisadores e grupos de pesquisa do antigo Iuperj, desde 2010. Na época, após uma crise com a instituição que o abrigava, a Universidade Cândido Mendes, por conta do repasse de recursos, o Iuperj foi rebatizado Iesp e passou a responder como programa de pós-graduação vinculado à Uerj. Para fins de sistematização, esta etapa do trabalho considerou as produções do Iuperj até 2009 de modo separado, dada a sua representatividade na área. E, a partir de 2010, integrou esta produção à Uerj, muito embora valha aqui a ressalva das particularidades de cada instituição e programa. Nesse sentido, a Uerj é um caso particular, uma vez que abrange a produção científica de pelo menos quatro diferentes PPGs: o PPGCOM, o PPCIS (Ciências Sociais), o Iesp e o PropEd (Educação). Das doze teses e dissertações defendidas sobre o tema na universidade, seis correspondem ao PPGCOM, uma ao PropEd, uma ao PPCIS e quatro ao Iesp (somente entre 2010 e 2012), o que confirma a tradição do programa nesta especialidade acadêmica.
} 
trabalho sobre o tema ao longo da carreira. Tal situação nos direciona para a conformação de esferas de influência e redes de pesquisa cujos principais interesses de algum modo se interseccionam, e cuja dinâmica é perceptível a partir da imagem abaixo (I1), que nos apresenta árvores de orientação, de acordo com os dados minerados na pesquisa.

Com o passar do tempo, podemos observar novas ramificações se originando a partir daqueles que, em princípio, eram orientandos de outros pesquisadores, e vão surgindo casos em que uma nova geração de pesquisadores passa a ocupar um espaço de relevância no cenário nacional. Este tipo de ocorrência é particularmente evidente quando os pesquisadores da primeira geração têm orientação regular na área temática, como é o caso de Marcus Faria Figueiredo (cuja descendência se faz notar nas orientações conduzidas por alguns de seus alunos, segundo I1), Venício Artur de Lima (que origina uma descendência a partir de Mauro Porto) e Rousiley Maia (a partir de Ângela Marques). Outro caso relevante é o de Muniz Sodré, principal orientador da especialidade na UFRJ. Embora com um total menor de orientações, confirmando o caráter disperso da instituição, sua presença é significativa no doutorado, e se traduz em uma geração intermediária também produtiva, cujos principais expoentes são Afonso de Albuquerque e Raquel Paiva.

Embora haja trabalhos sobre Comunicação e Política defendidos no Brasil desde os anos 70, e nossa análise mostre seu crescimento constante desde os anos 90, estas relações de filiação institucional, que correspondem a algo como "escolas" das quais o Doxa é exemplo, são raras. Há ainda uma clara predominância de árvores que se aglutinam em torno de uma única pessoa, mesmo no caso de orientadores antigos na especialidade. Neste sentido, percebemos uma grande quantidade de formações circulares fechadas, com maior ou menor número de orientandos, mas que não estabelecem uma continuidade. Incluímos neste caso círculos em que há um vínculo 
externo com seta de entrada, pois o orientador central fez sua tese ou dissertação na especialidade, mas o fez com um pesquisador que orientou poucos trabalhos na área.

Imagem I1: Árvores de orientação
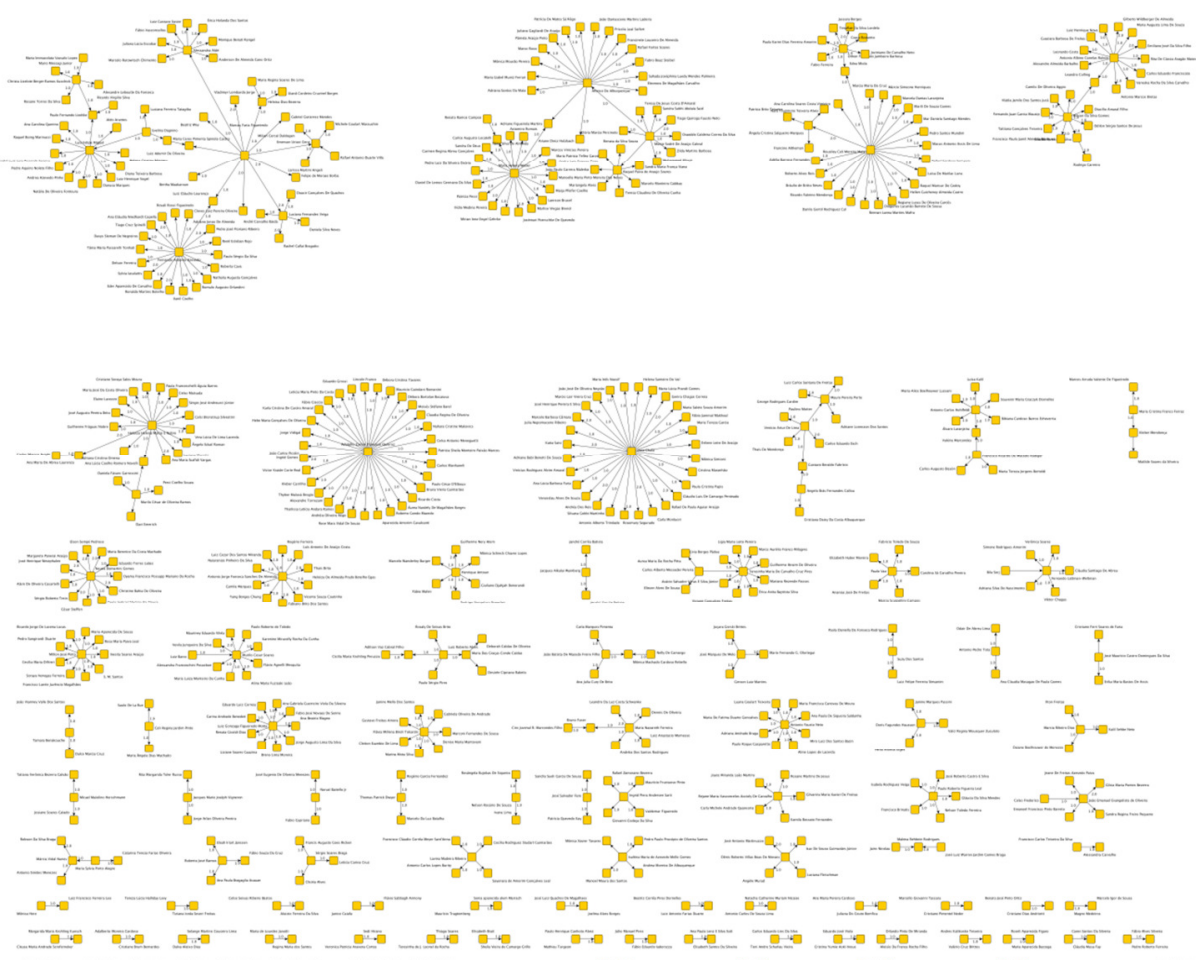
5 드.

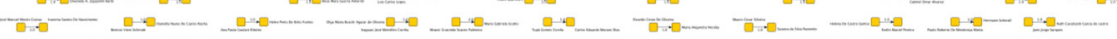

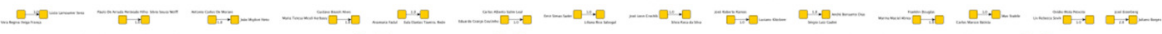
드.

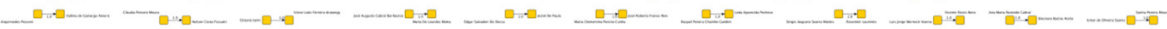

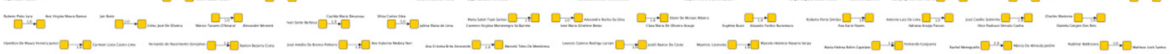
다.

Fonte: Compolítica.

Clique na imagem para vê-la ampliada.

Por outro lado, notamos vínculos de compartilhamento - quando um autor tem orientador diferente no mestrado e no doutorado, e ambos são orientadores produtivos, configurando, na nossa imagem, um ponto de conexão entre círculos ou árvores de orientação. Este tipo de orientação genealógica bifurcada pode indicar proximidades 
temáticas ou institucionais, com orientadores indicando - e orientandos descobrindo - continuidades e vínculos. Observando de perto as conexões entre as árvores, é possível estabelecer vários tipos de análise sobre como tem sido a dinâmica e evolução das orientações na especialidade.

É de se supor que os pesquisadores com maior quantidade de orientações detenham um grande capital na formação de quadros e no alcance de sua rede. Entretanto, é justamente o potencial rizomático dessas esferas de influência que denota a solidez dos grupos no panorama nacional e, de certo modo, contrabalança a extensão da influência direta. Outro aspecto importante novamente diz respeito à natureza dos trabalhos, uma vez que os pesquisadores com maior total de orientações nem sempre são aqueles com maior quantidade de orientações de doutorado e que, portanto, lidam com pesquisadores em vias de se afirmar como quadros efetivos em outras instituições (Q9).

Quadro Q9: Pesquisadores com mais de dez de orientações concluídas (ordenado por total de orientações)

\begin{tabular}{llllll}
\hline Nome & Instituição & $\begin{array}{l}\text { Orientações } \\
\text { de } \\
\text { mestrado }\end{array}$ & $\begin{array}{l}\text { Orientações } \\
\text { de } \\
\text { doutorado }\end{array}$ & $\begin{array}{l}\text { Total de } \\
\text { orientações }\end{array}$ \\
\hline $\begin{array}{l}\text { Vera Lucia Michalany } \\
\text { Chaia }\end{array}$ & PUC-SP & 23 & 11 & 34 \\
\hline $\begin{array}{l}\text { Adolpho Carlos } \\
\text { Françoso Queiroz }\end{array}$ & Umesp & 29 & 3 & 32 \\
\hline $\begin{array}{l}\text { Rousiley Celi Moreira } \\
\text { Maia }\end{array}$ & UFMG & 19 & 3 & 21 \\
\hline $\begin{array}{l}\text { Fernando Antônio } \\
\text { Azevedo }\end{array}$ & Ufscar & 17 & 4 & 18 \\
\hline $\begin{array}{l}\text { Maria Helena Weber } \\
\text { Neusa Demartini }\end{array}$ & UFRGS & 14 & 4 & 17 \\
\hline \begin{tabular}{l} 
Gomes \\
\hline
\end{tabular} & PUC-RS & 9 & & 23 \\
\hline
\end{tabular}




\begin{tabular}{lllll}
\hline $\begin{array}{l}\text { Heloiza Helena Matos } \\
\text { e Nobre }\end{array}$ & USP & 10 & 7 & 17 \\
\hline $\begin{array}{l}\text { Afonso de } \\
\text { Albuquerque }\end{array}$ & UFF & 14 & 2 & 16 \\
\hline $\begin{array}{l}\text { Marcus Faria } \\
\text { Figueiredo }\end{array}$ & Iuperj/Iesp & 6 & 9 & 15 \\
\hline $\begin{array}{l}\text { Antonio Albino } \\
\text { Canelas Rubim }\end{array}$ & UFBA & 4 & 7 & 14 \\
\hline Wilson da Silva Gomes & UFBA & 8 & 5 & 13 \\
\hline Luis Felipe Miguel & UnB & 10 & 2 & 11 \\
\hline Jorge Ameida & UFBA & 11 & 0 & \\
\hline
\end{tabular}

Fonte: Compolítica.

Ainda assim, perceber como operam estas redes é tarefa fundamental para um mapeamento como o nosso. E, portanto, o passo é, mais uma vez, procurar observar como estes pesquisadores atuam dentro de suas instituições. 


\section{Vera Chaia}

Aintonio Alloino Rübin

\section{Rousiley Maia}

\section{AdolphoCuerroz}

Luis Fellipe Miguel:

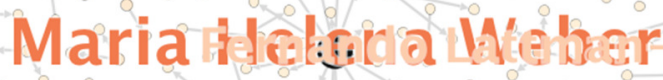

Afonso de Albuquerque

Heloiza Helenamatos e Nobre

Fernand(o)Azevedo

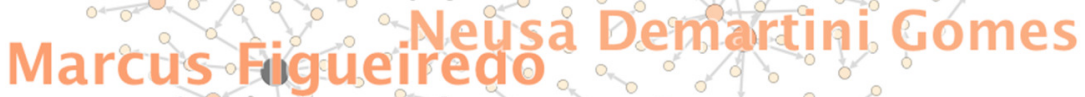

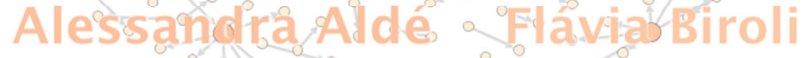

Fonte: Compolítica.

Clique na imagem para vê-la em tamanho ampliado.

Como vimos, a instituição com mais trabalhos defendidos foi a UFRJ (66), seguida de UnB (58), UFBA (55), USP (48), PUC-SP (46), PUC-RS (46) e Umesp (45). No entanto, estes números podem operar de forma diversa quando considerada a concentração de pesquisas por orientador. O que se conclui é que alguns dos programas com mais defesas dentro da especialidade da Comunicação Política são também aqueles com maior dispersão das orientações entre os docentes, sendo o caso mais expressivo, novamente, o da UFRJ. Dessa forma, os programas mais concentrados são aqueles que têm dimensões semelhantes nos dois gráficos. 
Imagem I4: Instituições com maior quantidade de trabalhos defendidos

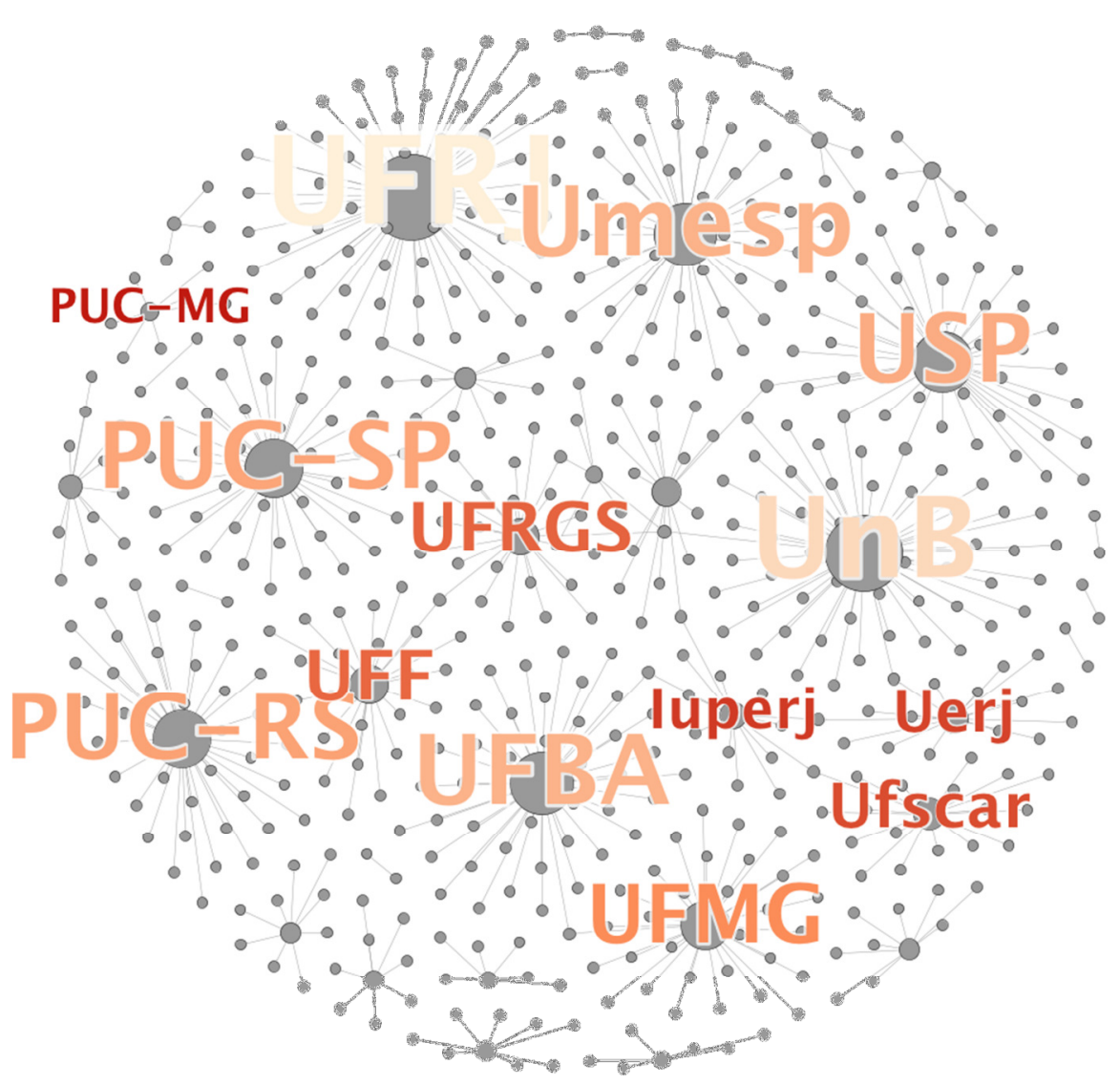

Fonte: Compolítica.

Clique na imagem para vê-la em tamanho ampliado.

Por fim, cumpre destacar que, em vista da enorme quantidade de dados disponíveis por meio deste mapeamento, muitas outras considerações são possíveis e vários outros entrecruzamentos de dados podem guiar nossas observações em futuros esforços. Aqui, entretanto, ficam registradas, para efeito de uma análise preliminar, algumas das questões que de imediato nos saltaram aos olhos. 


\section{Considerações finais}

Acreditamos que o levantamento realizado para o Diretório contribui para evidenciar a antiguidade, crescimento e consolidação da especialidade no Brasil. Ressaltamos a evolução na quantidade total dos trabalhos e na presença das teses de doutoramento; a inclusão progressiva de novas instituições, orientadores e temáticas; a confirmação de nossa interdisciplinaridade, com a participação de diversas áreas do conhecimento durante todo o período estudado. 0 volume mesmo de estudos dedicados a cada tema indica interesse acadêmico constante e crescente na Comunicação Política.

Por outro lado, a produção de teses e dissertações aponta para uma articulação ainda incipiente entre os esforços dos indivíduos e instituições dedicados ao tema. Trata-se de um campo relativamente pequeno se considerado em relação a cada área específica em que são defendidos os trabalhos - mesmo em Comunicação ou Ciência Política. Há poucos orientadores, em cada instituição, com foco na especialidade, geralmente um ou dois; a demanda discente, neste sentido, parece ser maior que os orientadores especialistas disponíveis, mobilizando um grande contingente de orientadores eventuais nas instituições. O volume de doutores ainda é pequeno, e seu crescimento nos últimos anos mostrou-se irregular. No sentido da formação de quadros pós-graduados, portanto, a Comunicação Política ainda inicia o processo de amadurecimento já conquistado em outras frentes de atuação acadêmica - como participação nas Associações e seus congressos, publicação em periódicos científicos e constituição de grupos de pesquisa ativos nacional e internacionalmente. Nossa expectativa, no entanto, é que os dados de 2012 e 2013, quando atualizados, já trarão modificações a este panorama. 
Imagem I5: Instituições e nomes dos mestres e doutores e Comunicação e Política

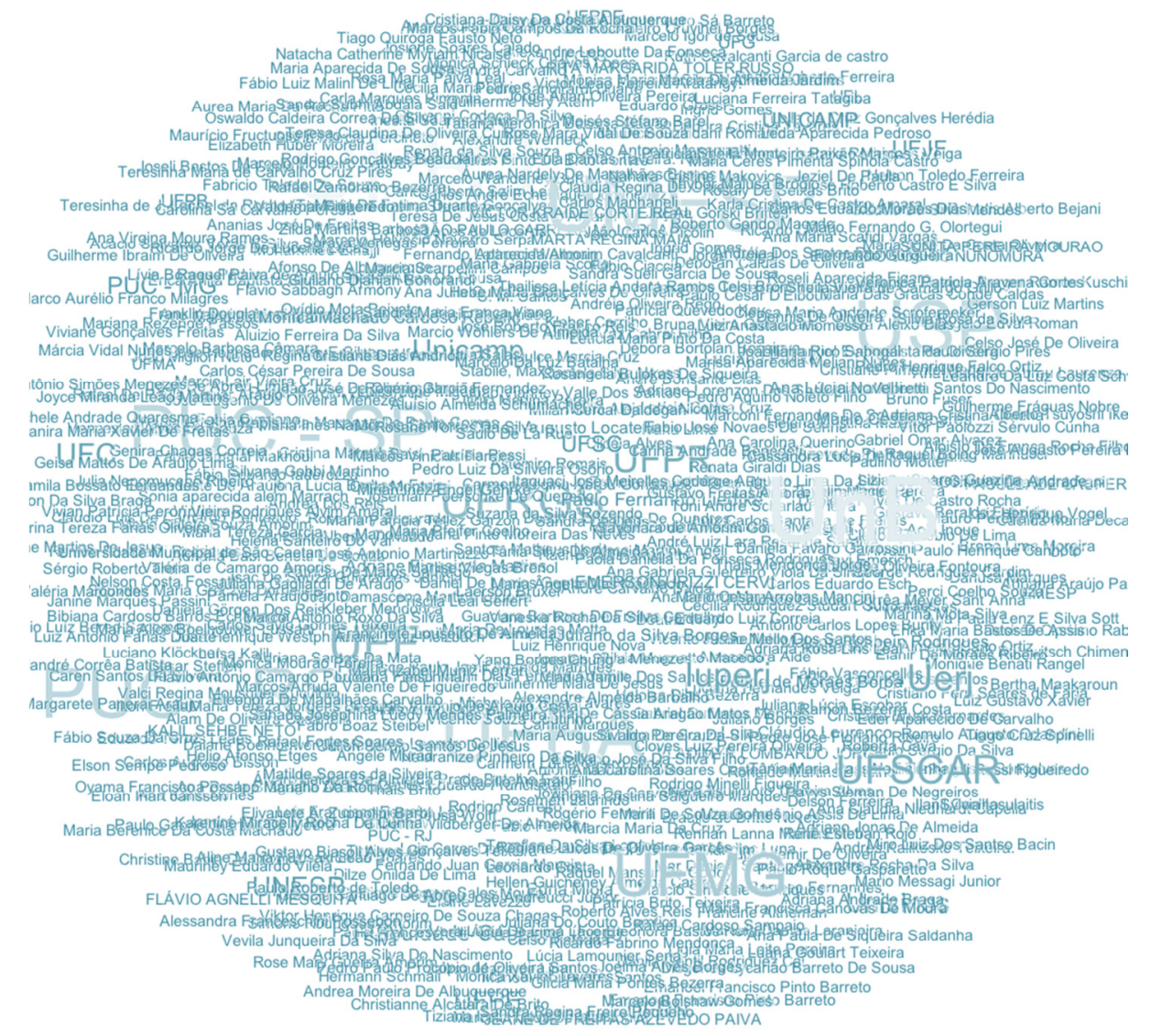

Fonte: Compolítica.
Clique na imagem para vê-la em tamanho ampliado.

COMPOIITICA ASSOCIACÃO BRASILEIRA DE PESQUISADORES EM COMUNICACAOO E POLITICA

Presidente: Alessandra Aldé (UERJ)

Vice-Presidente: Luis Felipe Miguel (UnB)

Secretário Executivo: Francisco Jamil Marques (UFC)

Editora-Chefe:

Alessandra Aldé (UERJ)

Editores Executivos:

Edna Miola (UFS) e Viktor Chagas (UFF)

Editores Assistentes:

Eleonora Magalhães (UFF) e Fernanda Sanglard (UERJ)

Revisor: Pedro Sangirardi (UERJ)
A Revista Compolítica é uma revista eletrônica da Associação Brasileira de

Pesquisadores em Comunicação e Política. Com periodicidade semestral, sua proposta é difundir a produção acadêmica relacionada às interfaces desses campos de estudo.

Ao citar este artigo, utilize a seguinte referência bibliográfica

ALDÉ, Alessandra; CHAGAS, Viktor; SANTOS, João Guilherme Bastos dos. Teses e dissertações defendidas no Brasil (1992-2012): um mapa da pesquisa em comunicação e política. In: Revista Compolítica, n. 3, vol. 2, ed. julho-dezembro, ano 2013. Rio de Janeiro: Compolítica, 2013. 
